\title{
Self-Aligning MEMS In-Line Separable Electrical Connector
}

\author{
Michael P. Larsson and Richard R. A. Syms, Senior Member, IEEE
}

\begin{abstract}
A MEMS in-line separable connector containing features for precision self-alignment is demonstrated. The concept relies on sliding connection between female and male halves to induce vertical deflections of a set of flexible conductors and establish stable electrical contacts. Electrodeposited photoresist is used to fabricate thick, nonplanar conductors, shaped by a silicon substrate that has previously been terraced by anisotropic etching. Further etched features ensure transverse and vertical self-alignment between conductor elements during mating. Prototype 10-way connectors are demonstrated with $200 \mu \mathrm{m}$ wide conductors on a $250-\mu \mathrm{m}$ pitch. Mechanical reliability of contacts during repeated mating and demating is demonstrated, and initial measurement of contact resistance reveals an encouraging value of $30 \mathrm{~m} \Omega$.

[1075]
\end{abstract}

Index Terms-MEMS connector, microconnector, micro contact, microelectromechanical systems (MEMS).

\section{INTRODUCTION}

$\mathbf{T}$ HE function of an electrical connector is to provide a separable interface between two subunits of an electronic system without adversely affecting performance [1]. For the manufacturer, separable connectors allow modular assembly, reducing lead-time and costs. For the user, subunit separability provides the option of repair or replacement.

Connector design is becoming more challenging as devices get smaller and signal frequencies rise. Miniature, high-density connectors capable of operating at gigahertz frequencies are commercially available (e.g., the "Micro-Pitch Connector" by Siemens Electromechanical Components $\mathrm{GmbH}$ [2]). Because such devices are manufactured by pressing and injection moulding, the scope for further miniaturization is limited. Microelectromechanical systems (MEMS) technology extends the scope of miniaturization at potentially lower cost. The application of MEMS to electrical switching and RF devices is quite advanced. However, relatively little attention has been focused on electrical connectors, despite their potential for high-density interconnections.

Withinelectricalengineering, thereare requirementsforseveral types of connectiondevice.Eachisconstructeddifferently, and has a different function. The main types are cable connectors, board connectors, chipconnectors and probe testers. Attempts have been made todevelopMEMSembodiments of each, as wenow describe.

Cable connectors make a (normally demountable) connection between two electrical cables. They are referred to as in-line

Manuscript received June 24, 2003; revised October 21, 2003. Subject Editor H. Fujita.

The authors are with the Optical and Semiconductor Devices Group, Department of Electrical and Electronic Engineering, Imperial College London, London SW7 2BT, U.K. (e-mail: r.syms@imperial.ac.uk).

Digital Object Identifier 10.1109/JMEMS.2004.825238 connectors, if the connection is made by insertion of a male part into a female part, in a direction parallel to the cable axis. The cable may have many conductors. If these lie parallel in a plane, the connector is often known as a ribbon connector. In a ribbon connector, the connecting elements (often known as tongues) are normally arranged on a substrate. The tongues may then deflect in plane (i.e., parallel to the substrate plane) or out-of-plane (perpendicular to the substrate). Thus, it is possible to have an in-line connector with in-plane deflection of the connector tongues.

The most advanced MEMS connectors are in-line, in-plane ribbon connectors fabricated using LIGA (Lithographie, Galvanoformung und Abformung) and UV-LIGA processes, by Ehrfeld [3] and Unno [4], respectively. In each case, the connector tongues are fabricated by electroplating into deep moulds formed in thick photoresist. Fig. 1(a) shows a LIGA connector by Ehrfeld. Since the tongues open parallel to the substrate, there is (as we show later) a tradeoff between interconnect density and contact force in this geometry. In other designs, the elements open perpendicular to the substrate. Fig. 1(b) shows an out-of-plane device by Lemke [5], formed by etching crystalline silicon. In each case, precision alignment of the connector halves becomes increasingly important as the connection density rises. However, in each of Fig. 1(a) and $1(\mathrm{~b})$, alignment is achieved only in a single direction.

Board connectors may connect circuit boards to cables (in which case they are known as edge connectors) or boards to other boards (in which case they are known as motherboard connectors). Edge connectors are typically in-line devices, while motherboard connectors often connect boards at right angles. The connection is again usually demountable. Toshiyoshi [6] and Tixier [7] have developed motherboard connectors in which cavities are etched in Si by deep reactive ion etching to create "fingers," which are then coated in a conductive layer. However, the fingers deflect in plane.

Strandman [8] and Boyle [9] have used cheap anisotropic etching to fabricate connectors with elastic elements in borondoped $\mathrm{Si}$ and $\mathrm{Si}_{3} \mathrm{~N}_{4}$, respectively. Although intended as passive fixing and alignment features for single mode fibers, this technology lends itself well to the possibility of connecting cables and microchips to a motherboard, provided the elastic elements are coated in a conductive material. As the elastic elements deflect out-of-plane, the tradeoff between interconnect density and contact force is significantly reduced.

Chip connectors typically connect integrated circuits to miniature boards inside an overall enclosure, in multichip module (MCM) assembly. The connection is usually permanent and made using solder. MEMS MCM connectors have been based on surface-mounted dies that are soldered onto tongues 


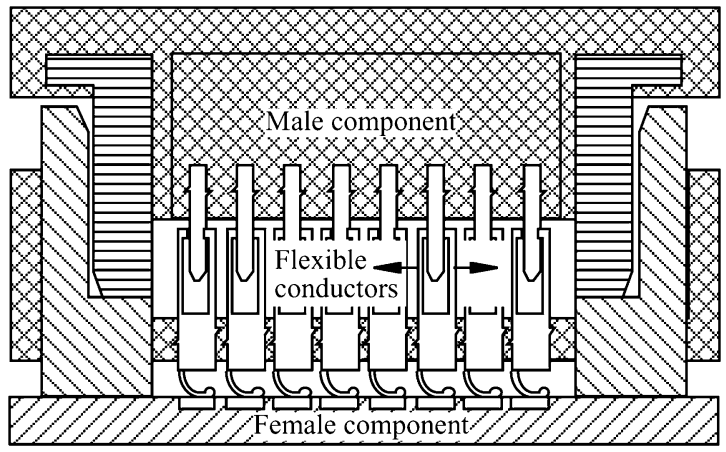

a)

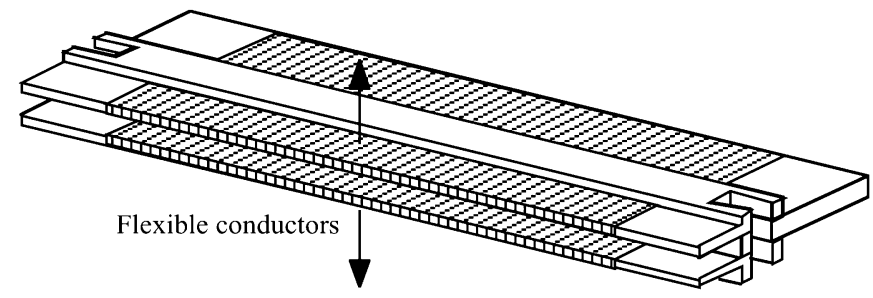

b)

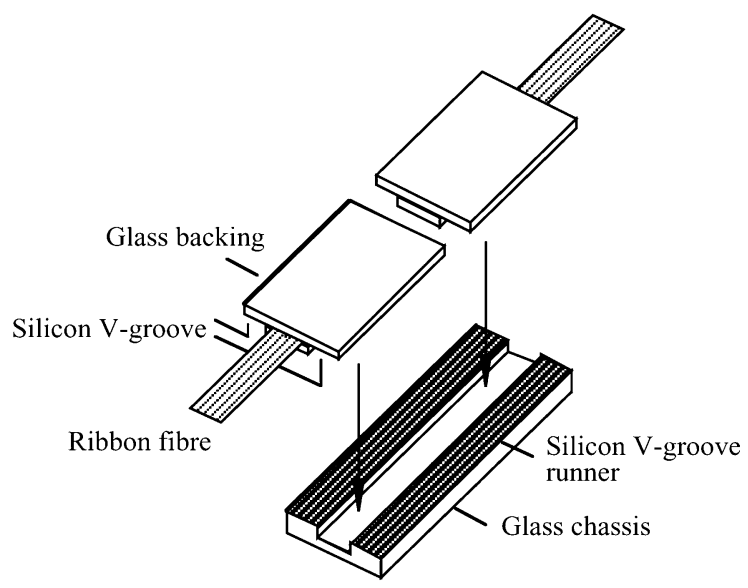

c)

Fig. 1. In-line connector designs by a) Ehrfeld and b) Lemke; c) self-aligning optical fiber connector by Holmes (adapted from [3], [5], and [20]).

resting parallel to the substrate [10]. The tongues are often shaped for transverse or longitudinal compliance, to relax thermal strains [11], [12].

Probe testers form a temporary connection to an integrated circuit during the quality inspection stage of manufacture. Here, the challenge is to fabricate conductors that can be elevated from the substrate to allow pressure contact with a set of points on the test device. MEMS probe testers have been fabricated by electroplating shaped conductors on nonplanar substrates [13], and by deflecting the conductor elements out-of-plane using electrothermal actuation [14]. MEMS probers are now being used for LSI testing [15].

In this paper, we describe an improved form of in-line cable connector, in which the elastic elements are designed to deflect out-of-plane at close to yield stress, providing a relatively large force from a compact design. Etched features on both connector halves are used to set the contact force and prevent short circuits, in an arrangement that is self-aligning in both lateral and vertical directions. The tongues are shaped, following concepts drawn from motherboard connectors, MCM connectors and probe testers. A
FEMALE PART

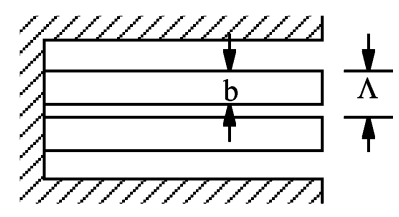

Substrate plane

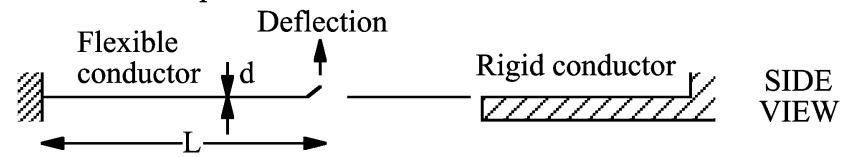

a)

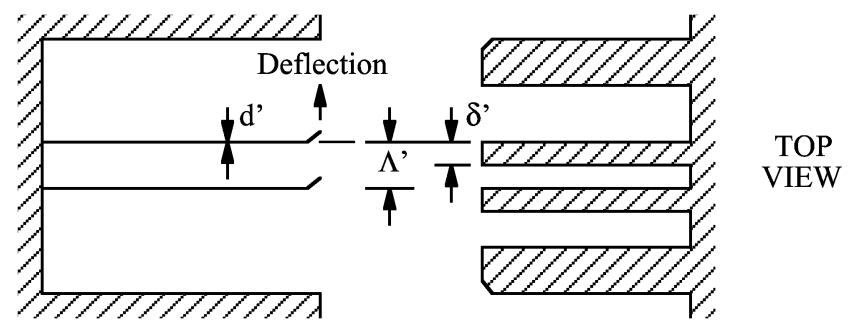

Substrate plane

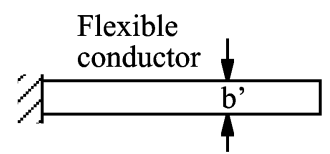

Rigid conductor

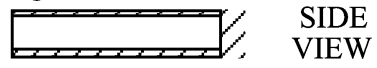

\section{b)}

Fig. 2. Schematic diagrams of a) out-of-plane and b) in-plane in-line connectors.

theoretical comparison of in-plane and out-of-plane connectors is first made in Section II, pointing out the differences between and common features of the two approaches. The design of a selfaligning connector is then presented in Section III, together with a low-cost fabrication process based on anisotropic etching and electroplating. Preliminary results of mechanical and electrical characterization are given in Sections IV and V, and conclusions are drawn in Section VI.

\section{THEORETICAL ANALYSIS}

The two approaches to in-line cable connectors may be compared using the examples in Fig. 2. Here, Fig. 2(a) and (b) show out-of-plane and in plane connectors, respectively. We start by considering the former, using a simple theoretical model based on straight cantilevers to generate approximate design rules. We assume that contact resistance-a key performance parameter-is most affected by the contact pressure and its area of application, i.e., by the contact force, which may be found as follows. According to simple theory [16], the local radius of curvature $\mathrm{r}$ of a bent beam is related to the moment $\mathrm{M}$, and the second moment of area I and Young's modulus E by $1 / \mathrm{r}=\mathrm{M} / \mathrm{EI}$. In standard approximations, $1 / \mathrm{r} \approx \mathrm{d}^{2} \mathrm{y} / \mathrm{dx}^{2}$, where $\mathrm{x}$ is the position along the beam and $y$ is the transverse displacement. If a load $\mathrm{F}$ is applied to a cantilever of length $\mathrm{L}$, the local moment is $\mathrm{M}=-\mathrm{F}(\mathrm{L}-\mathrm{x})$, and the beam bending equation may be integrated to obtain the tip deflection $\delta=-\mathrm{y}(\mathrm{L})$ as

$$
\delta=\frac{\mathrm{FL}^{3}}{3 \mathrm{EI}}
$$


For a rectangular section of breadth $\mathrm{b}$ and depth $\mathrm{d}, \mathrm{I}=\mathrm{bd}^{3} / 12$. The maximum moment occurs at the cantilever root and is $\mathrm{M}_{\max }=-\mathrm{FL}$. The longitudinal strain $\varepsilon$ is equal to $-\mathrm{y} / \mathrm{r}$, where $\mathrm{y}$ is the height above the neutral axis. Maximum strain $\varepsilon_{\max }$ occurs when $\mathrm{y}= \pm \mathrm{d} / 2$. The corresponding stress $\sigma_{\max }=\varepsilon_{\max } \mathrm{E}$ is then

$$
\sigma_{\max }=\frac{6 \mathrm{FL}}{\mathrm{bd}^{2}}
$$

Combining (1) and (2), the end deflection may be related to the maximum stress as

$$
\delta=\left(\frac{2}{3}\right)\left(\frac{\sigma_{\max }}{\mathrm{E}}\right)\left(\frac{\mathrm{L}^{2}}{\mathrm{~d}}\right) .
$$

For elastic operation, the maximum stress $\sigma_{\max }$ should be lower than the yield stress $\sigma_{\mathrm{y}}$ for the material. If an array of elastic conductors is used in an out-of-plane connector as in Fig. 2(a), and if the space between conductors may be neglected, the minimum pitch $\Lambda$ is approximately b. The yield load $\mathrm{F}_{\mathrm{y}}$ (which corresponds to the maximum contact force) is

$$
\mathrm{F}_{\mathrm{y}} \approx \frac{\sigma_{\mathrm{y}} \Lambda \mathrm{d}^{2}}{6 \mathrm{~L}}
$$

Equation (4) provides a simple estimate of the contact force that may be obtained for a given connector pitch, using elastic conductors of a given length and depth in a specified material.

Alternatively, if the conductors deflect in plane as in Fig. 2(b), the deflection and force may be obtained by analogy from (3) and (4), as $\delta^{\prime}=(2 / 3)\left(\sigma_{\mathrm{y}} / \mathrm{E}\right)\left(\mathrm{L}^{2} / \mathrm{d}^{\prime}\right)$ and $\mathrm{F}_{\mathrm{y}}^{\prime} \approx \sigma_{\mathrm{y}} \mathrm{b}^{\prime} \mathrm{d}^{\prime 2} / 6 \mathrm{~L}$, where $\mathrm{b}^{\prime}$ and $\mathrm{d}^{\prime}$ are now breadths and depths measured in a perpendicular direction. However, because the cantilevers now deflect in plane, we must consider the minimum achievable connector pitch more carefully.

We suppose that the deflection arises from the insertion of fixed conductors of individual width $\delta^{\prime}$ during mating. In this case, the connector pitch must be $\Lambda=\mathrm{d}^{\prime}+\delta^{\prime}$, or

$$
\Lambda=\mathrm{d}^{\prime}+\frac{\mathrm{K}_{\mathrm{y}}}{\mathrm{d}^{\prime}}, \quad \text { where } \mathrm{K}_{\mathrm{y}}=\left(\frac{2}{3}\right)\left(\frac{\sigma_{\mathrm{y}}}{\mathrm{E}}\right) \mathrm{L}^{2} .
$$

The pitch is clearly a more complex function of $\mathrm{d}^{\prime}$ than the equivalent relation for an out-of-plane device. By differentiation, it can be shown that pitch has a minimum value, which is obtained when $\mathrm{d}^{\prime}=\sqrt{ } \mathrm{K}_{\mathrm{y}}$ or $\Lambda=2 \mathrm{~d}^{\prime}$. The maximum contact force may then be found as

$$
\mathrm{F}_{\mathrm{y}}^{\prime} \approx \frac{\sigma_{\mathrm{y}} \mathrm{b}^{\prime} \Lambda^{2}}{24 \mathrm{~L}}
$$

Assuming a similar value of $\mathrm{L},(4)$ and (6) imply that $\mathrm{F}_{\mathrm{y}}>\mathrm{F}_{\mathrm{y}}^{\prime}$ if $\mathrm{d}^{2}>\mathrm{b}^{\prime} \Lambda / 4$, or if $\Lambda<4 \mathrm{~d}^{2} / \mathrm{b}^{\prime}$. If the conductors are formed in each case by electroplating into a mould, we might expect $\mathrm{d}$ and $\mathrm{b}^{\prime}$ to be limited by lithography to a maximum value $\mathrm{D}$. We then find that $\mathrm{F}_{\mathrm{y}}>\mathrm{F}_{\mathrm{y}}^{\prime}$ if $\Lambda<4 \mathrm{D}$. The out-of-plane device will therefore provide a greater contact force, and hence a lower contact resistance, for pitches less than four times the maximum conductor depth. Assuming that $D$ must be less than (say) $50 \mu \mathrm{m}$ with conventional lithography, we would expect an advantage to be reached for $\Lambda<200 \mu \mathrm{m}$. A similar conclusion is reached if there is more than one elastic conductor per connection, as in Fig. 1(a).

Of course, there are actually two contributions to the overall input resistance $R_{I}$ in a connector: track resistance $R_{T}$ and contact resistance $R_{C}$. For an out-of-plane device, the track resistance is simply $\mathrm{R}_{\mathrm{T}}=\rho \mathrm{L} / \mathrm{bd}$, where $\rho$ is the resistivity of the conductor material. According to Holm [17], the resistance for a low force, elastic contact varies according to

$$
\mathrm{R}_{\mathrm{C}}=\mathrm{kF}_{\mathrm{y}}^{-\frac{1}{3}}
$$

Here, $\mathrm{k}$ is a constant that depends on the elastic and electrical properties of the conductor material and on the surface roughness. Equations (4) and (7) suggest that $R_{C}$ will depend on $L^{1 / 3}$, so that both contributions to $R_{I}$ vary as $L$ raised to a positive power. The optimum approach is therefore to reduce $\mathrm{L}$ as far as possible. The analysis above suggests that infinite contact force will be obtained for infinitely short beams subjected to infinitely small deflections. This conclusion is erroneous, because shear (which dominates as the length of the beam reduces compared with its depth) is neglected, and because finite contact deflections are required in practice. There is, therefore, a lower limit to conductor length, and an upper limit to contact force. Additional limits to miniaturization are set by the need for accurate alignment of closely spaced conductors.

\section{CONNECTOR DESIGN AND FABRICATION}

In this section, the design of a 10-way electrical connector is presented, and a low-cost fabrication process based almost entirely on anisotropic wet chemical etching [18], [19] of 4-inch diameter (100) silicon wafers is described. Although the dimensions of this initial demonstrator are relatively large, the process can be developed to reduce conductor pitch.

\section{A. Design}

The design uses substrate terracing to shape conductors into a 3-D profile, to allow deflections normal to the substrate. Additional features are incorporated into the substrate to obtain precise alignment between conductor elements. These features were originally developed for ribbon optical fiber connectors by Holmes [20], as in Fig. 1(c). Here, anisotropic etching is used to form rails in one part and grooves in the other. The parts interlock to enable transverse and vertical alignment between the two halves of the connector, and hence the low loss required in a single-mode fiber connector.

Fig. 3 shows how this principle may be used in an electrical connector. Fig. 3(a) shows the female part, which carries shaped elastic conductors with a raised contact area. Fig. 3(b) shows the male part, which carries flat, rigid conductors. Fig. 3(c) shows the parts after mating. Here, alignment rails and trenches (on the female and male parts, respectively) allow precise, sliding connection between both sets of conductors. The front face of the male part is sloped by anisotropic etching. This feature, together with the shape of the elastic conductors, allows smooth depression of the conductors into the underlying cavity. At present, 


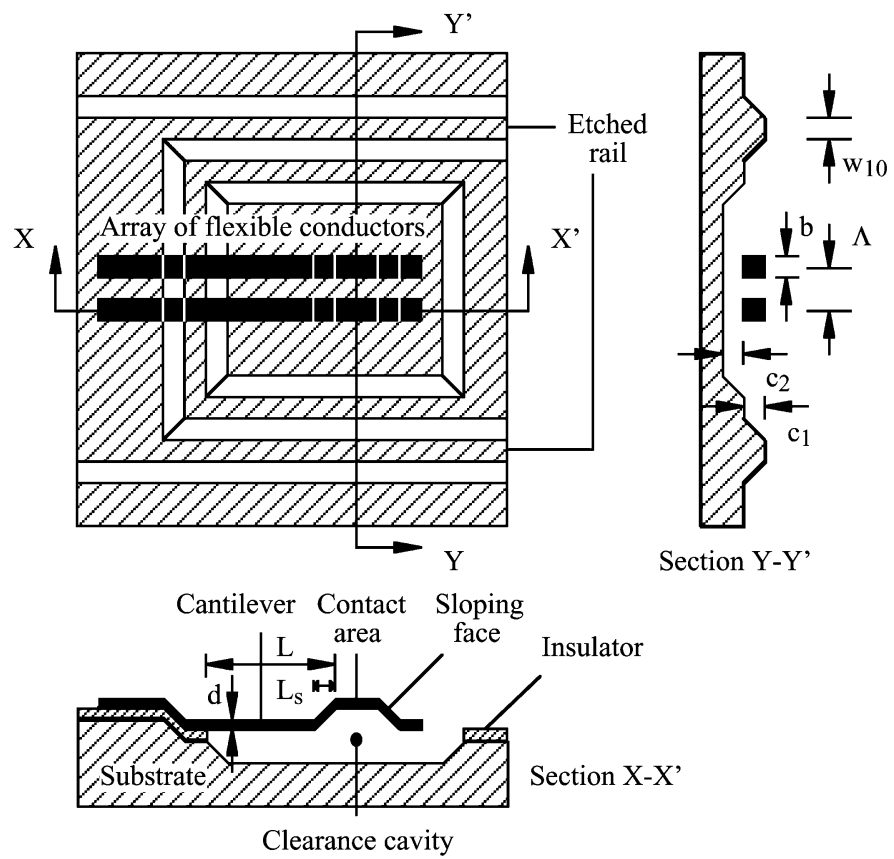

a)

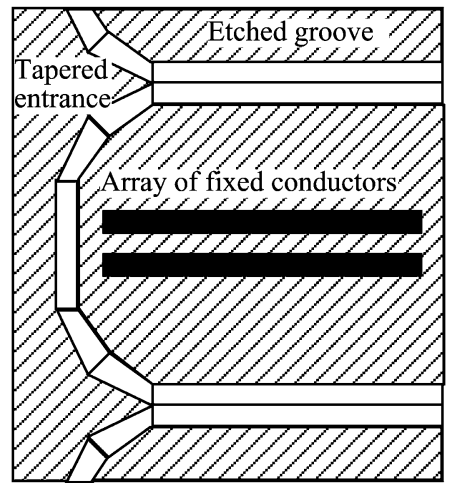

b)

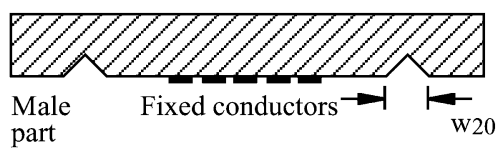

Female Flexible conductors
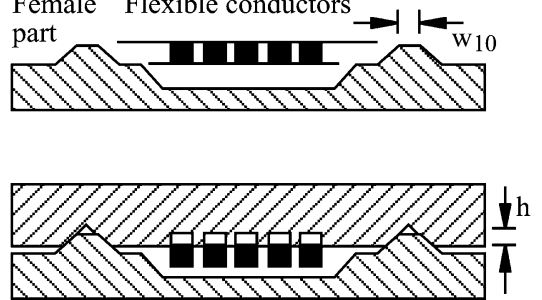

c)

Fig. 3. Self-aligning MEMS electrical connector based on nonplanar conductors: a) female part, b) male part, and c) alignment of male and female parts during connector mating.

there is no mechanical lock to hold the two halves of the connector together after mating; however, it is expected that one will be incorporated in future designs.

Anisotropic etching of (100) silicon forms features defined by (111) planes. The angle $\theta$ between the (100) and (111) planes is

$$
\theta=\cos ^{-1}\left(\frac{1}{\sqrt{ } 3}\right)=54.74^{\circ} \text {. }
$$

Relative feature heights on the mated connector may be found in terms of mask widths $\mathrm{w}_{10}$ and $\mathrm{w}_{20}$, defining the width of the rail on the female part and the trench on the male part. At a distance $\mathrm{h}$ from the surface, the widths $\mathrm{w}_{1}$ and $\mathrm{w}_{2}$ of these features are

$$
\begin{aligned}
& \mathrm{w}_{1}=\mathrm{w}_{10}+2 \mathrm{~h} \cot (\theta) \\
& \mathrm{w}_{2}=\mathrm{w}_{20}-2 \mathrm{~h} \cot (\theta) .
\end{aligned}
$$

When the two parts are placed together, the rail-trench overlap height $\mathrm{h}$ can be found by solving (9), assuming $\mathrm{w}_{1}=\mathrm{w}_{20}$ or $\mathrm{w}_{2}=\mathrm{w}_{10}$. In either case

$$
\mathrm{h}=\left(\frac{\Delta \mathrm{w}}{2}\right) \tan (\theta)=\frac{\Delta \mathrm{w}}{\sqrt{ } 2} .
$$

Here, $\Delta \mathrm{w}=\mathrm{w}_{20}-\mathrm{w}_{10}$. Thus, $\mathrm{h}$ is determined only by mask dimensions. Assuming that the thickness of both male and female conductors is $\mathrm{d}$ (which they may be if both halves of the connector are formed on a common substrate), the deflection $\delta$ at the contact region is

$$
\delta=\mathrm{h}+2 \mathrm{~d}
$$

This deflection is required in an estimation of the contact force and maximum stress, which may be found from (2), (3), (4), (10), and (11). Although these equations were developed for flat cantilevers, they provide good estimates for shaped cantilevers over the range of parameters used here. Later experimental work showed that the final contact point lay (to a reasonable approximation) at the top of the sloping element immediately adjacent to the main cantilever section. The "true" cantilever shape therefore consists of a straight horizontal section of length $\mathrm{L}-\mathrm{L}_{\mathrm{s}}$ linked to a sloping section of projected length $\mathrm{L}_{\mathrm{s}}$, as shown in Fig. 3(a). Provided the sloped element does not buckle, the deflection of this geometry under a point end-load $\mathrm{F}$ may be found using simple beam bending theory as

$$
\delta=\left(\frac{\mathrm{FL}^{3}}{3 \mathrm{EI}}\right) \times \mathrm{f}, \quad \text { where } \mathrm{f}=\left\{1+(\sqrt{ } 3-1)\left(\frac{\mathrm{L}_{\mathrm{s}}}{\mathrm{L}}\right)^{3}\right\}
$$


1. Form terraced substrate by $\mathrm{KOH}$ etch of $\mathrm{Si}$

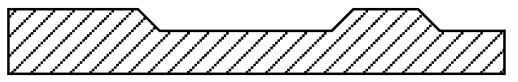

2. Grow insulator; pattern

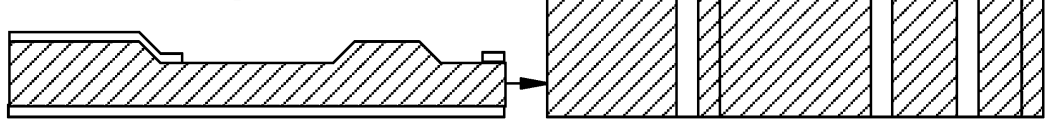

3. Deposit plating seed layer

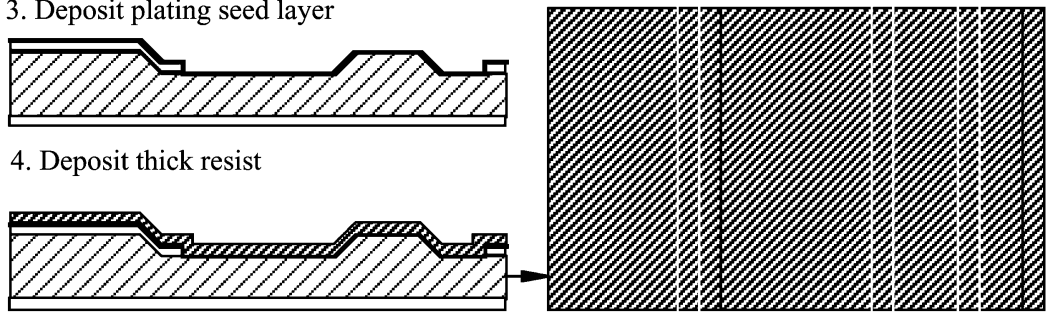

5. Expose and develop to form deep mold

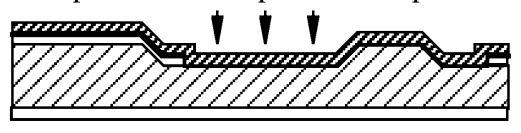

6. Electroplate into deep mold

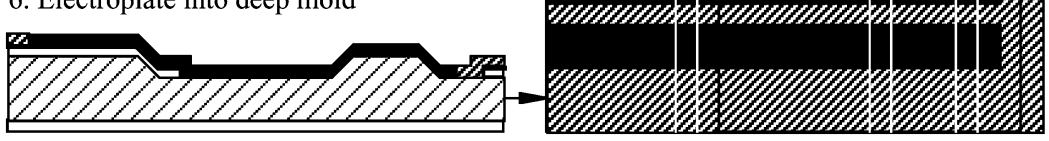

7. Strip resist and plating seed layer

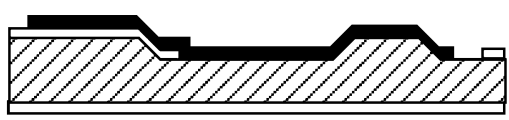

8. Undercut conductors
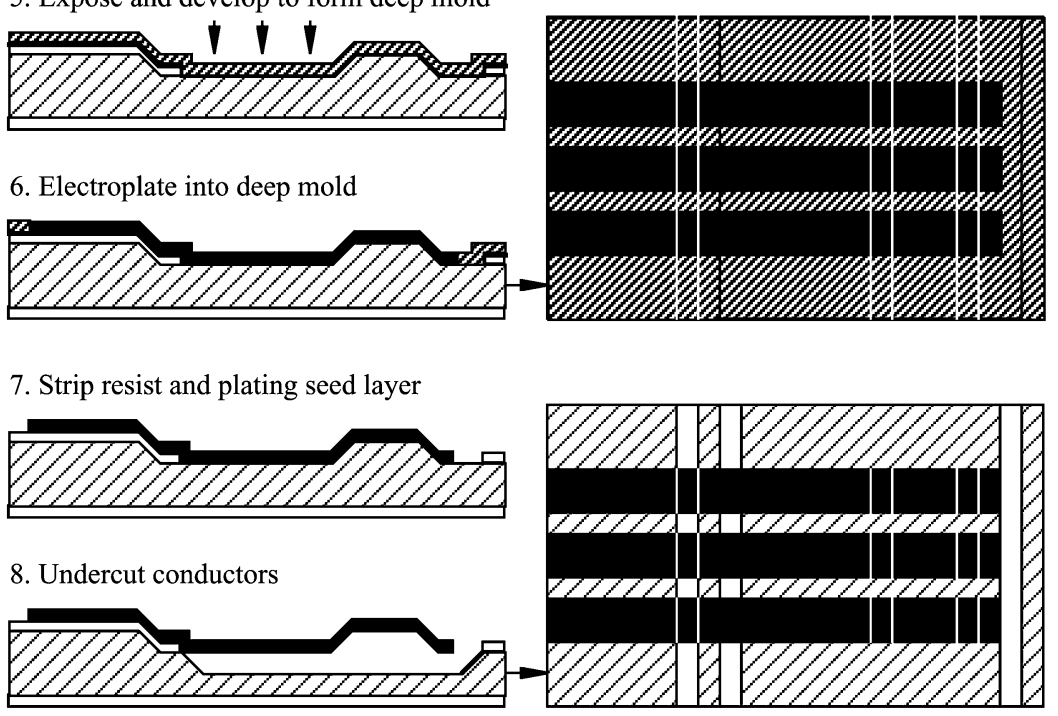

Fig. 4. Process for fabricating nonplanar conductors.

Equation (12) is clearly similar to (1), with the exception of a correction factor $\mathrm{f}$ that depends on the fraction of the overall length taken up by the sloped section. The function $\mathrm{f}$ varies smoothly from unity (when $\mathrm{L}_{\mathrm{s}} / \mathrm{L}=0$ ) to a maximum of $\sqrt{ } 3$ (when $\mathrm{L}_{\mathrm{s}} / \mathrm{L}=1$ ). Because of the cubic dependence on $\mathrm{L}_{\mathrm{s}} / \mathrm{L}$, $\mathrm{f}$ differs from unity by fractions of a percent for small $\mathrm{L}_{\mathrm{s}} / \mathrm{L}$, which is the case for all parameter combinations here.

\section{B. Fabrication}

A three-mask process was developed to fabricate prototype connectors. Fig. 4 shows the steps involved. The substrate is first terraced to form alignment and surface shaping features, by anisotropic etching of (100)-oriented silicon in potassium hydroxide $(\mathrm{KOH})$ solution heated to $75^{\circ} \mathrm{C}$, using $80 \mathrm{~nm}$ thickness of $\mathrm{Si}_{3} \mathrm{~N}_{4}$ as a surface mask. After removal of the mask, a $1.5-\mu \mathrm{m}$-thick layer of thermal silica is grown, to provide isolation between the conductors and the substrate. This layer is patterned, to define a mask for a later step that creates a clearance cavity. The conductor elements are then formed, by electroplating within a deep photoresist mould. The conductors consist of $20-\mu \mathrm{m}$-thick nickel as the structural material, with a $2-\mu \mathrm{m}$-surface layer of gold to reduce the contact resistance. The Ni layer was formed using a $65 \%$ nickel sulphamate solution (UN3082 by Schlotter Plating Technology Ltd.) operating at $50^{\circ} \mathrm{C}, \mathrm{pH} 4.0$ and a current density of $10 \mathrm{~mA} / \mathrm{cm}^{2}$. The $\mathrm{Au}$ layer was formed using a potassium cyanide solution (E59 by Engelhard-Clal Ltd.), operating at $35^{\circ} \mathrm{C}$ and a current density of $2 \mathrm{~mA} / \mathrm{cm}^{2}$. Plating is carried out on a sputter deposited seed layer, consisting of $100 \mathrm{~nm} \mathrm{Cu}$ metal on $50 \mathrm{~nm} \mathrm{Cr}$. The resist mould is then removed, and the clearance cavity is formed by a second anisotropic etching step.

\section{Design Parameters}

The theory of Section II allows the design of suitable elastic conductor dimensions using mechanical property data for $\mathrm{Ni}$ and other constituent materials obtained from the literature, as shown in Table I. Here, values are given for bulk [21] and electrodeposited [22] $\mathrm{Ni}$. The main differences in the two forms appear to be in material strength, with electrodeposited $\mathrm{Ni}$ having higher values of yield stress and ultimate tensile 
TABLE I

Properties of Constituent Metals, Taken From Bulk Data [21] UnLess Otherwise Stated

\begin{tabular}{l|l|l|l|l}
\hline Material & $\alpha\left(\times 10^{-6} \mathrm{~K}^{-1}\right)$ & $\rho\left(\times 10^{-8} \Omega \mathrm{m}\right)$ & $\mathrm{E}(\mathrm{GPa})$ & $0.2 \%$ offset $\sigma_{\mathrm{y}}(\mathrm{MPa})$ \\
\hline $\mathrm{Au}$ & 14.20 & 2.05 & 78.0 & - \\
\hline $\mathrm{Cr}$ & 4.90 & 12.70 & 279.1 & - \\
\hline $\mathrm{Cu}$ & 16.50 & 1.55 & 129.8 & - \\
\hline $\mathrm{Ni}$ & 13.40 & 6.20 & $199.5\left(176.0^{*}\right)$ & $59.0\left(323.0^{*}\right)$ \\
\hline
\end{tabular}

(*properties for electrodeposited $\mathrm{Ni}$, from [22])

TABLE II

Estimated BENDing STRESSES AND CONTACT ForCES FOR DifFERENT PARAMETER COMBINATIONS

\begin{tabular}{|c|c|c|c|c|c|c|c|c|}
\hline $\begin{array}{l}\mathrm{L} \\
(\mu \mathrm{m})\end{array}$ & $\begin{array}{l}\Delta \mathrm{w} \\
(\mu \mathrm{m})\end{array}$ & $\begin{array}{l}\delta \\
(\mu \mathrm{m})\end{array}$ & $\begin{array}{l}\sigma_{\max } \\
(\mathrm{MPa})\end{array}$ & $\begin{array}{l}\mathrm{F} \\
(\mathrm{mN})\end{array}$ & $\begin{array}{l}\Delta \mathrm{w} \\
(\mu \mathrm{m})\end{array}$ & $\begin{array}{l}\delta \\
(\mu \mathrm{m})\end{array}$ & $\begin{array}{l}\sigma_{\max } \\
(\mathrm{MPa})\end{array}$ & $\begin{array}{l}\mathrm{F} \\
(\mathrm{mN})\end{array}$ \\
\hline 500 & 35 & 69 & 892.6 & 28.8 & 75 & 97 & 1254.8 & 40.5 \\
\hline 700 & 35 & 69 & 455.4 & 10.5 & 75 & 97 & 640.2 & 14.8 \\
\hline 900 & 35 & 69 & 275.5 & 4.9 & 75 & 97 & 387.3 & 6.9 \\
\hline 1100 & 35 & 69 & 184.4 & 2.7 & 75 & 97 & 259.3 & 3.8 \\
\hline 1300 & 35 & 69 & 132.0 & 1.6 & 75 & 97 & 185.6 & 2.3 \\
\hline 1500 & 35 & 69 & 99.2 & 1.1 & 75 & 97 & 139.4 & 1.5 \\
\hline
\end{tabular}

strength. The mechanical properties of plated $\mathrm{Ni}$ depend strongly on mean current density, which affects grain size, material texture and porosity. Low current densities yield fine columnar microstructures, resulting in layers of high strength and stiffness, whilst high current densities yield coarser micro-structures of low strength and stiffness. Values of $0.2 \%$ offset yield stress in the range 323-450 MPa have been reported for various plating current densities [22]-[25]. For Young's modulus, the differences are less systematic. Some reports suggest values for plated material closer to that of bulk [26], while others suggest lower values in the range 176-180 GPa [22], [23], [27]. The lower values have been attributed to the presence of out-of-plane (001) texture [23] and porosity-induced cracking [24]

Female parts were designed with a range of conductor lengths, to allow variation of the contact force. Male trench widths were varied for the same reason. Component dimensions were deliberately exaggerated to facilitate manual mating, and male conductor tracks were short-circuited to allow single-ended measurement of contact resistance at the female end.

Key dimensions were as follows. The conductor length $\mathrm{L}$ was varied between $500 \mu \mathrm{m}$ and $1500 \mu \mathrm{m}$ in steps of $50 \mu \mathrm{m}$, while the conductor thickness d was $22 \mu \mathrm{m} \pm 20 \%$. The conductor width b was $200 \mu \mathrm{m}$, and the pitch $\Lambda$ was $250 \mu \mathrm{m}$. The female rail width $\mathrm{w}_{10}$ was maintained at $300 \mu \mathrm{m}$. Male trench widths $\mathrm{w}_{20}$ were varied between 335 and $375 \mu \mathrm{m}$, so that $\Delta \mathrm{w}$ ranged between 35 and $75 \mu \mathrm{m}$. These parameter variations allowed conductor deflections $\delta$ in the approximate range 60-100 $\mu \mathrm{m}$, depending on the conductor thickness and any static deflection. To ensure that the sloping face of the male part makes a sliding contact with the elastic conductor, the profile height $c_{1}$ (the rise and fall of the conductor shape) must be greater than the largest value of $\mathrm{h} ; \mathrm{c}_{1}=100 \mu \mathrm{m}$ was assumed. The clearance $\mathrm{c}_{2}$ beneath the conductors was $200 \mu \mathrm{m}$. Male and female dies measured $5 \mathrm{~mm} \times 8 \mathrm{~mm}$ and $10 \mathrm{~mm} \times 8 \mathrm{~mm}(\mathrm{~L} \times \mathrm{W})$, respectively.

Contact forces and maximum stresses were estimated from (2), (3), (4), (10), and (11), assuming for simplicity that beams were constructed entirely from $\mathrm{Ni}$ and neglecting their profile. Table II shows results obtained with different parameter combinations. Clearly, maximum stresses increase as beam lengths decrease and deflections increase. Some combinations were deliberately designed to exceed the yield stress estimate in Table I, as the true yield stress was uncertain, and because conductor thickness could easily be varied.

\section{Lithographic Requirements}

Early trials highlighted difficulties in spin coating of photoresist onto nonplanar substrates. Coverage was highly nonuniform, and of insufficient thickness along feature edges to provide a mould for plating. An alternative lithographic process was developed, based on an electrophoretic photoresist, Shipley Eagle ED2100 [28], [29]. Electrodeposition may conveniently be carried out on the seed layers used for later conductor deposition, and offers the major advantage of a uniform coating thickness over large topographic features. The limits to profile height are then set by optical diffraction during lithographic exposure, which degrades resolution.

The variables controlling the ED2100 thickness are applied voltage, electrolyte temperature and deposition time. Trials conducted to establish the relationship between coating thickness and temperature, at constant applied voltage and 


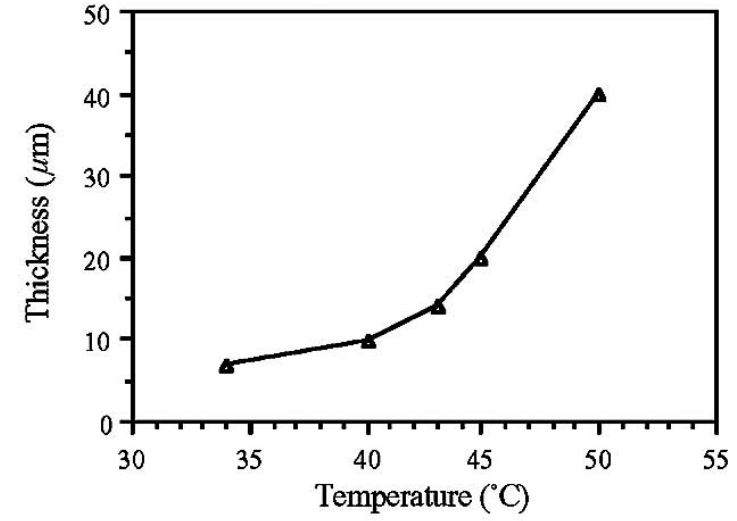

a)

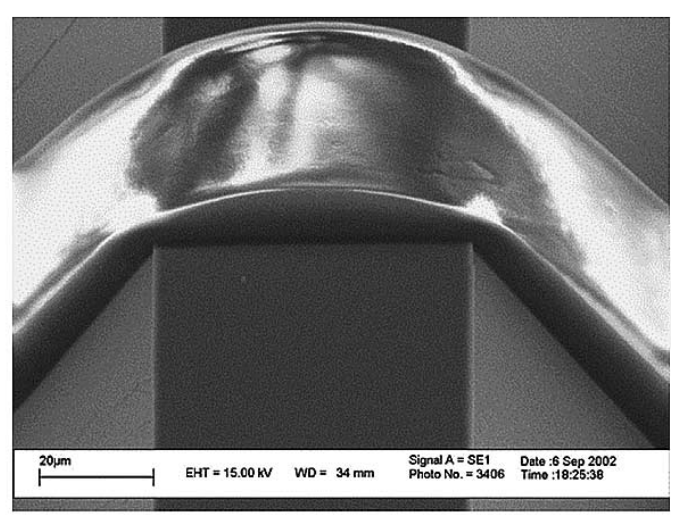

b)

Fig. 5. a) Variation of thickness with temperature for ED2100 photoresist, after electrodeposition for $120 \mathrm{~s}$ at $60 \mathrm{~V}$. b) Detail over $100 \mu \mathrm{m}$ high-etched mesa.

deposition time, reveal the trend shown in Fig. 5(a). Near uniform coatings of thickness greater than $20 \mu \mathrm{m}$ were deposited at temperatures above $45{ }^{\circ} \mathrm{C}$ [see Fig. 5(b)]. Such coatings allowed the formation of $22-\mu \mathrm{m}$-thick elastic conductors with profile heights in excess of $100 \mu \mathrm{m}$. However, variations in resolution typically decreased design widths from $200 \mu \mathrm{m}$ to between $190 \mu \mathrm{m}$ and $180 \mu \mathrm{m}$.

Male and female components were fabricated on a common substrate, and then separated into dies. Fig. 6(a) shows a completed female part. The shaped elastic conductors may clearly be seen, overhanging a clearance cavity. Fig. 6(b) shows a male part. Here, enhanced etching at initially convex corners [18], [19] has generated tapers at the extremities of the alignment trenches, which facilitate initial location during mating.

\section{Mechanical Characterization}

This section presents the results of initial mechanical characterization. Microcontacts have previously been investigated using special equipment capable of applying fine deflections [30] or measuring small loads [31]. The connector described here allows measurements to be performed using the structure itself, because components with different alignment features may be combined to give different deflections. The factors of interest are the mechanical properties of conductors (surface roughness, Young's modulus, residual stress and thermal expansion) and their behavior on mating (reliability and wear).

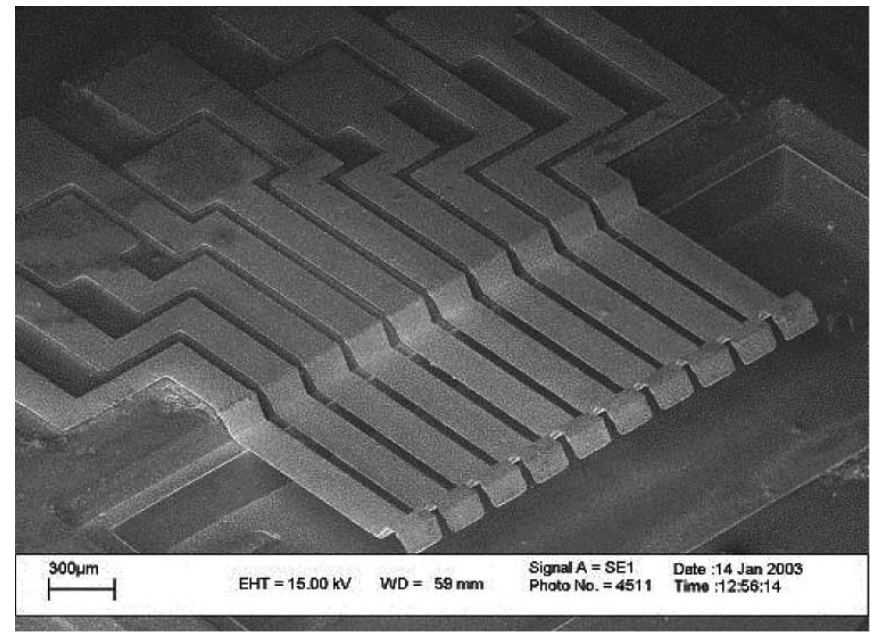

a)

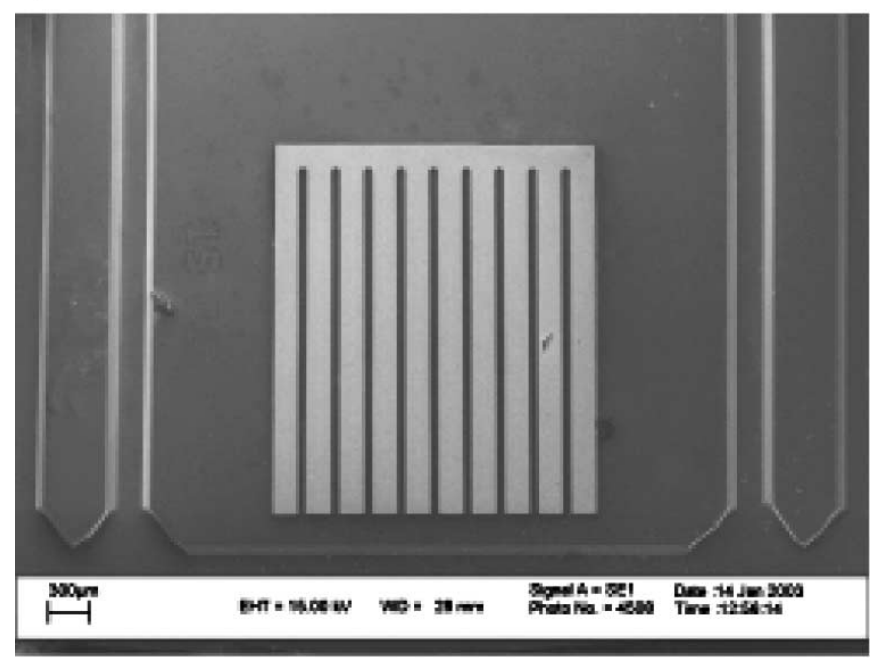

b)

Fig. 6. Completed MEMS connector components: a) female and b) male.

\section{A. Surface Roughness and Young's Modulus}

It is widely accepted in the literature that when two rough surfaces touch, high peaks, known as asperities, come into contact first, so that true contact area is only a small fraction of apparent area [32]. The number of contacting asperities depends on surface roughness and contact force. If the force is increased, the number of contacting asperities increases, and those already in contact deform plastically until the new contact area can support the new force [33]. Trials were conducted to ascertain the influence of current density on the surface roughness and Young's modulus of electroplated nickel. Flat Ni conductors were produced, by electroplating as described in Section III. A Dektak III surface profiler was used first to measure the roughness in the anchored regions [see Fig. 7(a)] and then to apply sliding point-loads in the suspended regions and measure ensuing deflections [see Fig. 7(b)]. The latter data were then used to estimate Young's modulus as described in [34].

The results reveal almost constant surface roughness and Young's moduli for plating current densities within the range 3 $\mathrm{mA} / \mathrm{cm}^{2}$ to $20 \mathrm{~mA} / \mathrm{cm}^{2}$ (with plating thickness maintained at $20 \mu \mathrm{m} \pm 20 \%$ ). Average values for average surface roughness 

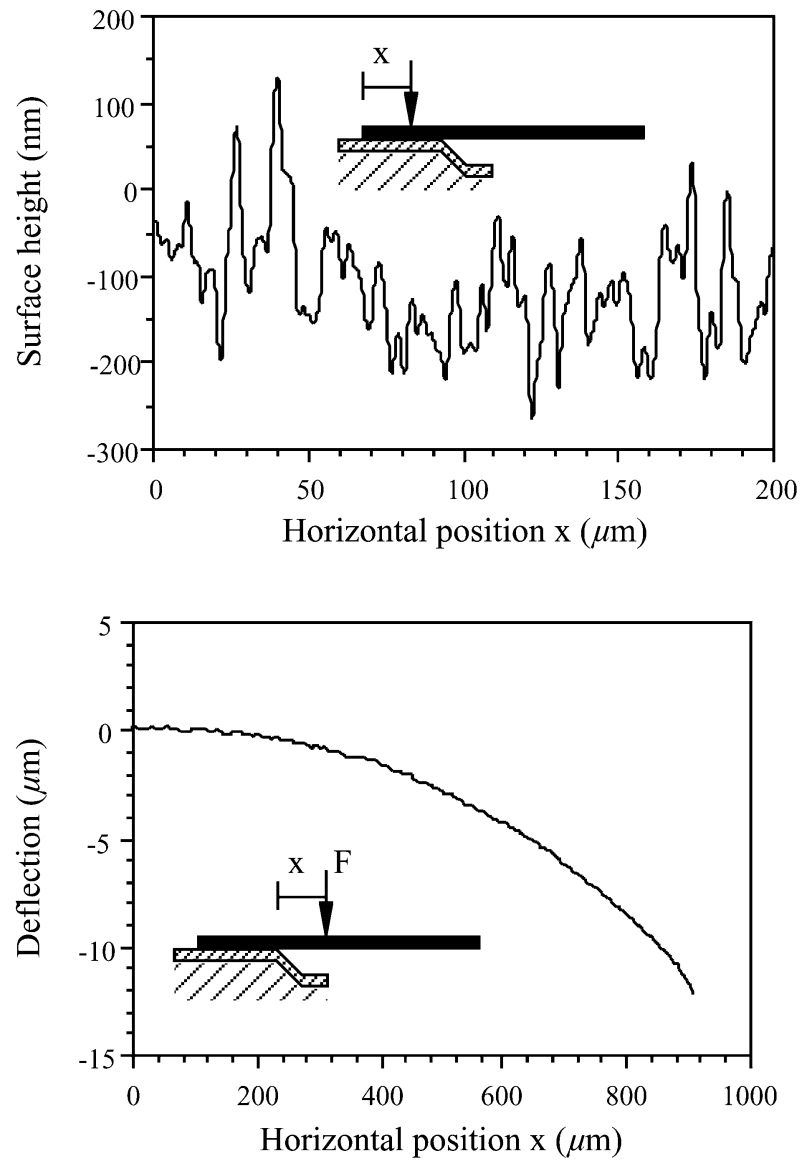

a)

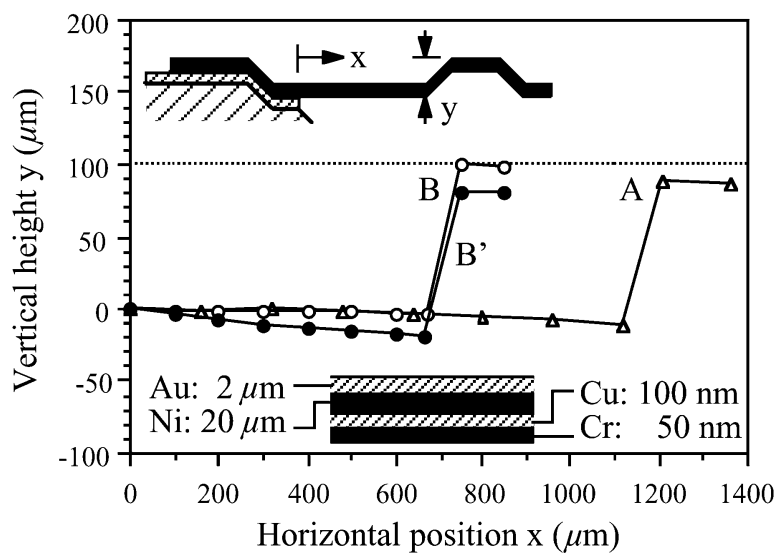

c)

Fig. 7. a) Variation of surface roughness Ra with position; b) deflection characteristic for a flat conductor element under $40 \mathrm{mg}$ moving point load; c) static profile of long (A) and short (B) spring conductor, and of short conductor after plastic deformation $\left(\mathrm{B}^{\prime}\right)$.

(Ra) and Young's modulus of $57 \mathrm{~nm}$ and $98 \mathrm{GPa}$, respectively, were obtained. The latter value is relatively low compared with previously published data [22], [23], [27].

\section{B. Residual Stress and Thermal Stability}

Optical measurements were also made to quantify any static tip deflections in released spring conductors. Fig. 7(c) shows the static profile of two typical elastic conductors, one long (trace A) and one short (B). In the former case the vertical profile height of the conductor is approximately $100 \mu \mathrm{m}$ and the static deflection at the contact region is $10 \mu \mathrm{m}$. These static deflections will tend to reduce the contact force from the estimated values.

Since each conductor is a quad-metallic strip, consisting mainly of $\mathrm{Ni}$ on a $\mathrm{Cr}-\mathrm{Cu}$ seed layer, with a thin surface layer of $\mathrm{Au}$, intrinsic stress and differential thermal expansion between the layers can both induce deflections. In a thermal bimorph of length $L$, formed from two materials of thickness $d_{1}$ and $\mathrm{d}_{2}$, with linear thermal expansion coefficients $\alpha_{1}$ and $\alpha_{2}$ and Young's moduli $\mathrm{E}_{1}$ and $\mathrm{E}_{2}$, respectively, the deflection of the tip $\delta_{\text {th }}$ caused by a temperature rise $\Delta \mathrm{T}$ is $\delta_{\text {th }}=\mathrm{L}^{2} / 2 \mathrm{r}_{\text {th }}$. If $\mathrm{d}_{2} \gg \mathrm{d}_{1}$, the curvature is given by [35]

$$
\frac{1}{\mathrm{r}_{\mathrm{th}}} \approx 6 \Delta \mathrm{T}\left(\alpha_{1}-\alpha_{2}\right)\left(\frac{\mathrm{d}_{1} \mathrm{E}_{1}}{\mathrm{~d}_{2}{ }^{2} \mathrm{E}_{2}}\right) .
$$

If the distortion is induced by residual stress $\sigma_{\text {res }}$ in a deposited layer rather than by thermal mismatch, a similar calculation yields a tip deflection $\delta_{\text {res }}=\mathrm{L}^{2} / 2 \mathrm{r}_{\text {res }}$, where the curvature is given by a one-dimensional (1-D) form of Stoney's formula [16]

$$
\frac{1}{\mathrm{r}_{\mathrm{res}}} \approx 6 \sigma_{\mathrm{res}} \frac{\mathrm{d}_{1}}{\mathrm{~d}_{2}^{2} \mathrm{E}_{2}} \text {. }
$$

At the level of approximation involved in (13) and (14), the effects of multiple strain-inducing layers are additive, and the overall deflection $\delta$ during contact modifies to:

$$
\delta=\mathrm{h}+2 \mathrm{~d}-\delta_{\text {res }}-\delta_{\text {th }}
$$

The Cr layer was identified as being responsible for the small static downward deflections in Fig. 7(c). Using elastic coefficients taken from Table I, the residual tensile stress in this layer was found to range between $0.0078-0.0136 \mathrm{GPa}$, for several female components.

Using linear thermal expansion coefficients taken from Table I, thermal deflections were computed to assess the contributions of individual layers on the main conductor constituent, nickel. The $\mathrm{Au}$ (whose expansion coefficient is greater than $\mathrm{Ni}$ ) and $\mathrm{Cr}$ (whose expansion coefficient is less than $\mathrm{Ni}$ ) both give a downward deflection as the temperature is raised. However, the results indicated that a rise of $10^{\circ} \mathrm{C}$ would induce a negligible downward deflection of $0.16 \mu \mathrm{m}$ for the longest $(1500 \mu \mathrm{m})$ beams considered here. To verify this, a female part was thermally cycled. The component was placed on an aluminum platform located on a Peltier heat pump, using conductive paste to ensure thermal transfer. Deflections were measured using an optical microscope equipped with a height gauge from Mitutoyo, which had a resolution of $1 \mu \mathrm{m}$. No measurable deflections of the metal parts within this resolution were found over the temperature range 0 to $60^{\circ} \mathrm{C}$. However, deflections of the substrate (which carries a thick silica isolation layer, and hence also functions as a thermal bimorph) of the order of a few microns were observed.

\section{Reliability and Contact Wear}

The resilience of elastic conductors to buckling and contact wear was qualitatively assessed through a series of sliding mating cycles. Male parts were first placed on female parts ahead of elastic conductors to ensure alignment. Mating was then achieved by sliding the male component along the female rails until electrical contact was established. Fig. 8(a) shows mated components after sliding connection. The alignment features are shown in Fig. 8(b).

A female-male connector set was subjected to a series of mating and de-mating cycles to assess the effect of repetitive 


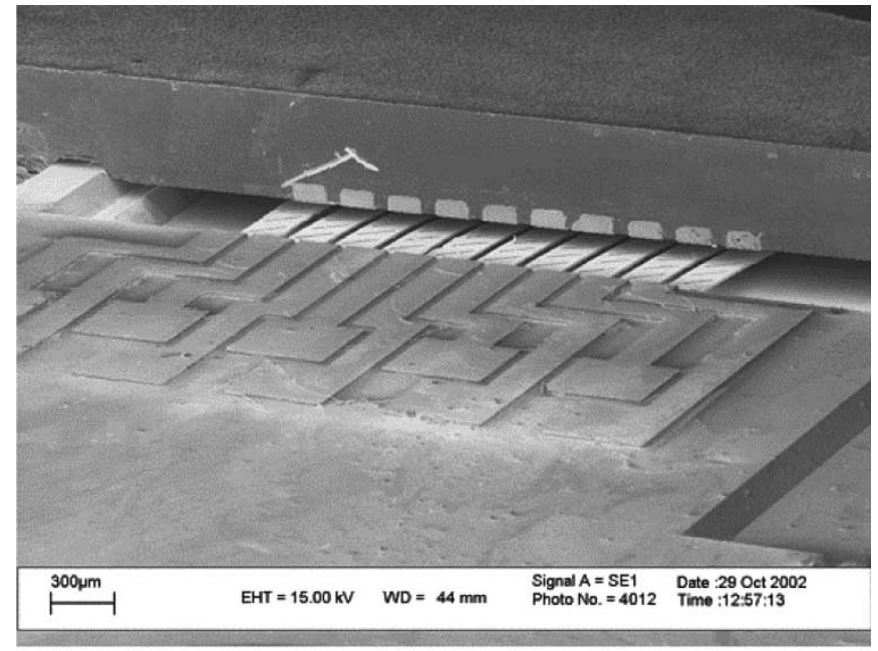

a)

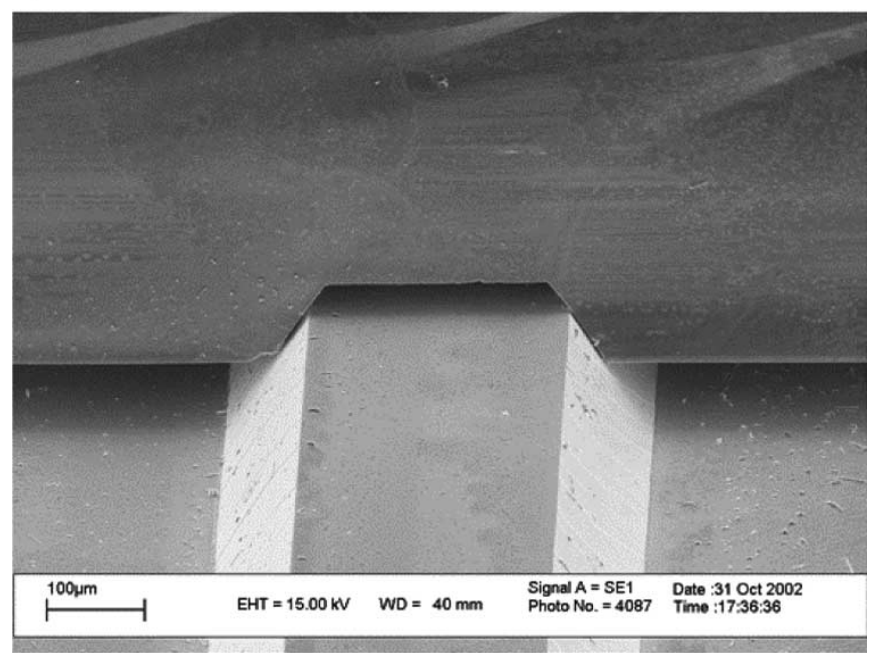

b)

Fig. 8. a) Mated connector halves after sliding connection and b) detail of alignment features.

sliding contacts. Fig. 9(a) and (b) shows abrasions sustained at the contact region of an elastic conductor after 5 and 50 mating cycles, respectively. Striations resulting from initial contact with the male component are seen along the front edge of the contact region. Further insertion of the male part causes separation between the front edge and the male conductor track. The contact region then briefly shifts to the flat section between front and back edges and finally moves to the back, where electrical contact is ultimately established. Variations in contact region geometry between female parts result in slightly different abrasion patterns and contact geometries. For example, Fig. 9(c) shows the striations on a different female part to that in Fig. 9(a) and (b). Here, the striation pattern suggests that electrical contact initially occurs only on the side edges of the conductor during mating, before moving to the back edge, resulting in a variable contact area.

Plastic deformation occurred for short conductors subjected to large deflections. For example, a permanent set of $\approx 23 \mu \mathrm{m}$ was seen in conductors with $\mathrm{L}=750 \mu \mathrm{m}$, under a design deflection of $\delta=100 \mu \mathrm{m}$. This data is superimposed on Fig. 7(c),

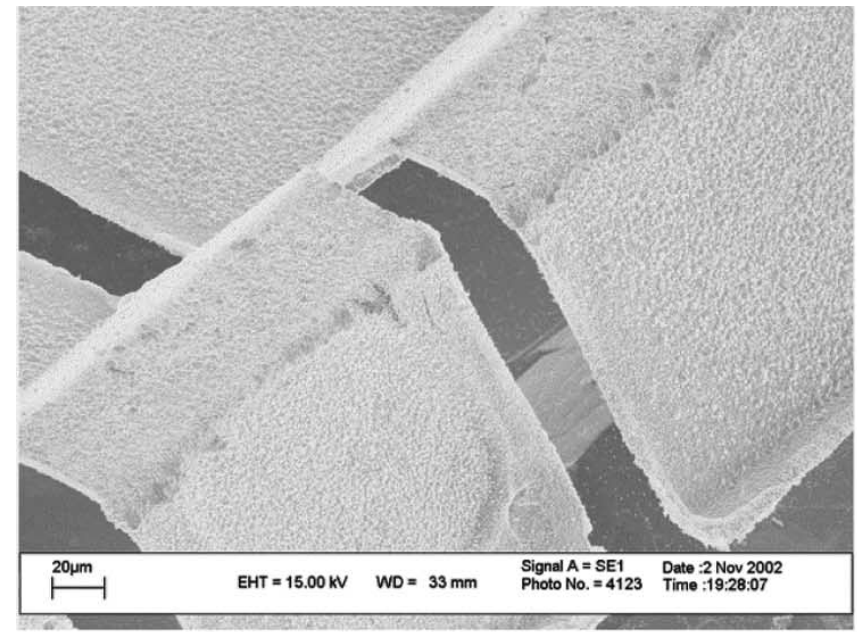

a)

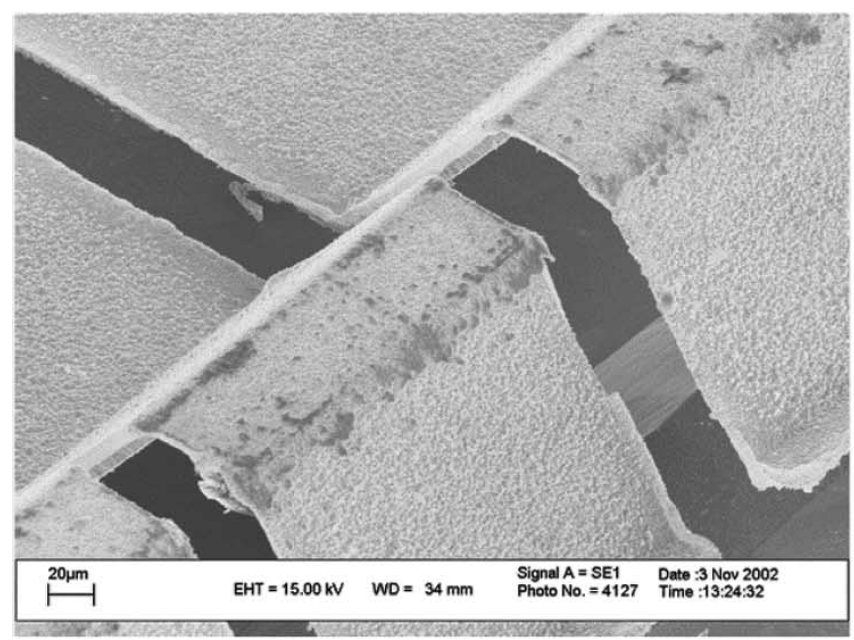

b)

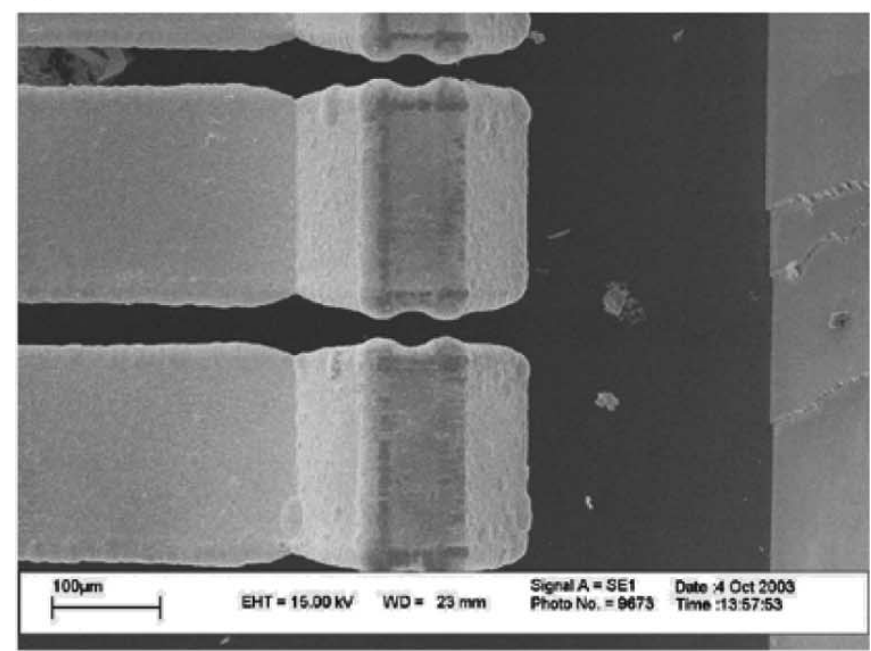

c)

Fig. 9. Abrasions on conductor contact region after a) 5 and b) 50 mating cycles. c) Characteristic abrasion patterns on nonplanar contact regions.

as trace $\mathrm{B}^{\prime}$. The profile of the plastically deformed conductor shows the presence of a plastic hinge at the fixed support, where the bending stress is at a maximum. For longer conductors, the 
permanent set was indistinguishable from the static deflection. These observations suggest a yield stress for the plated Ni higher than the bulk value in Table I, in agreement with Mazza [26]. However, the data were insufficiently repeatable to obtain a numerical value for $\sigma_{\mathrm{y}}$. Despite the observation of plastic deformation, stubbing of the conductors did not occur, even after repetitive mating.

\section{ELECTRICAL CHARACTERIZATION}

In this section, the results of initial electrical characterization are provided. The properties of a variety of contact materials have already been explored [36], [37], and contact resistance and reliability have been measured in experiments performed with RF MEMS switches [38]. The main factors of interest here are the conductivity of conductor elements, contact resistance and stability of contact resistance.

\section{A. Conduction Resistance}

Initially, there was a concern that the gold coatings would be removed or contaminated during anisotropic etching. A four-point probe was therefore used to measure the resistance of different lengths of conductor. Multiplying the gradient $\mathrm{dR} / \mathrm{dL}$ of each data set by the conductor width $\mathrm{b}$ yielded sheet resistivities $R_{\mathrm{s}}$ of $3.74 \mathrm{~m} \Omega$ and $4.18 \mathrm{~m} \Omega$ before and after immersion in $\mathrm{KOH}$ for 4.5 hours at $75{ }^{\circ} \mathrm{C}$, respectively. By comparison, the expected sheet resistivity was found from

$$
\frac{1}{\mathrm{R}_{\mathrm{s}}}=\frac{\mathrm{d}_{\mathrm{Au}}}{\rho_{\mathrm{Au}}}+\frac{\mathrm{d}_{\mathrm{Ni}}}{\rho_{\mathrm{Ni}}} \text {. }
$$

Here $\mathrm{d}_{\mathrm{Au}}$ and $\mathrm{d}_{\mathrm{Ni}}$ are the thickness of the gold and nickel layers, respectively, and $\rho_{\mathrm{Au}}$ and $\rho_{\mathrm{Ni}}$ are their bulk resistivities. Using data from Table $\mathrm{I}$, a value of $\mathrm{R}_{\mathrm{s}} \approx 2.4 \mathrm{~m} \Omega$ is obtained. This result confirms a consistent, though slightly high, conductor resistivity.

\section{B. Contact Resistance}

Single-ended four-point probe measurements were carried out on a series of mated test components to obtain contact resistance data. A range of contact forces was generated, by using combinations of female and male parts that provided different conductor lengths and deflections. Data was taken from components with similar abrasion patterns.

Contact resistances were estimated by measuring the resistance $R_{I I}$ between adjacent contact pads on the female component, when the male component was inserted. Since the male part contained an internal short-circuit, the contact resistance $\mathrm{R}_{\mathrm{C}}$ could be found as

$$
\mathrm{R}_{\mathrm{C}}=\frac{\left(\mathrm{R}_{\mathrm{II}}-2 \mathrm{R}_{\mathrm{T}}\right)}{2}
$$

Here, $R_{T}$ is a track resistance, estimated from the dimensions and sheet resistivity of the track. $\mathrm{R}_{\mathrm{II}}$ was determined from the voltage between the pads and the current. A consistent observation was that $\mathrm{R}_{\mathrm{II}}$ increased and decreased with increasing and decreasing current, respectively, in a hysteretic fashion. For example, Fig. 10(a) shows the variation of $\mathrm{R}_{\mathrm{II}}$ with current, averaged over three cycles of current variation. Stable circuit resistances were obtained for currents in excess of $\approx 150 \mathrm{~mA}$. SEM inspection did not reveal any local melting of asperities. The most likely explanation is Joule heating, which causes the conductors to deflect downwards due to differential thermal expan-

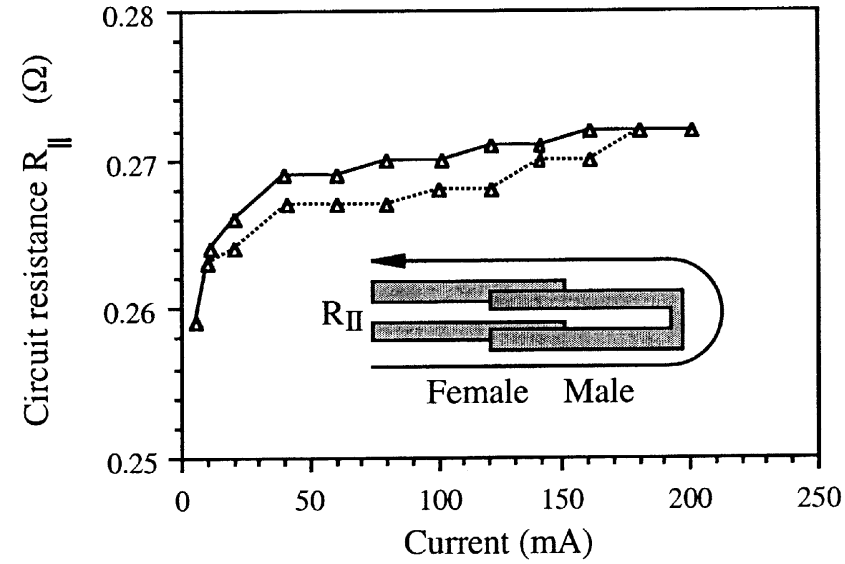

a)

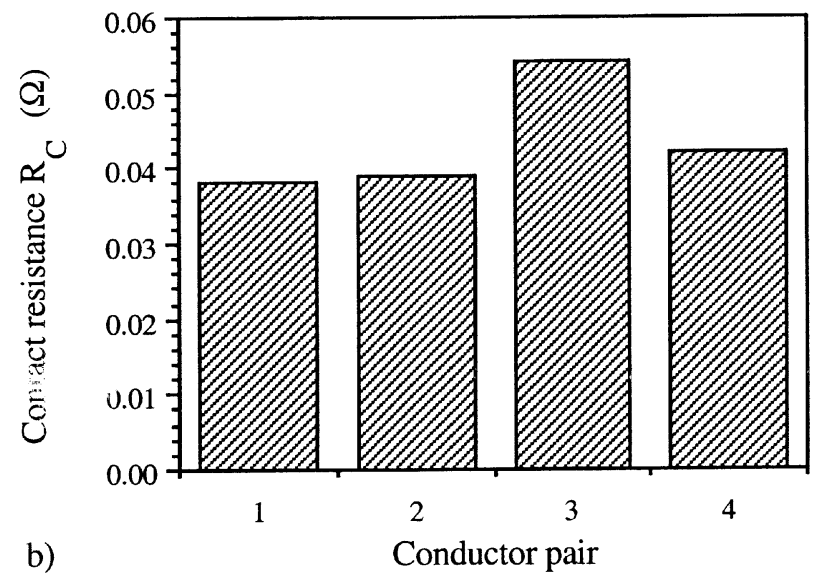

Fig. 10. a) Variation of circuit resistance $\mathrm{R}_{\mathrm{II}}$ with current during ramp-up and ramp-down tests. b) Variation of $\mathrm{R}_{\mathrm{C}}$ across one connector set.

sion, thus decreasing the contact force and increasing the contact resistance.

Contact resistances were determined from data obtained in the high-current regime. The calculated values reduced as the contact force increased, even after the plastic limit had apparently been passed. However, because of the variability in the data and the sensitivity of $R_{C}$ to variations in the conductor dimension and sheet resistivity, it was not possible to obtain conclusive agreement with the Holm model of (7). The variability is most likely due to differences in contact geometry and surface contamination. Fig. 10(b) shows contact resistances extracted from four circuit pairs on the same connector set. The set had spring conductors with $\mathrm{L}=1150 \mu \mathrm{m}$ and a design deflection of $\delta=85 \mu \mathrm{m}$, giving an estimated contact force of $2.3 \mathrm{mN}$. Despite the spread in the data, an average contact resistance of $43 \mathrm{~m} \Omega$ is obtained. A second connector set with spring conductors generating higher average contact forces of $5.9 \mathrm{mN}$ gave a lower average contact resistance of $30 \mathrm{~m} \Omega$.

\section{Wear Dependence of Contact Resistance}

The sensitivity of contact resistance to sliding wear was also investigated. Fig. 11(a) shows the variation in $\mathrm{R}_{\mathrm{C}}$ with mating cycle number on a connector set with $\mathrm{L}=1350 \mu \mathrm{m}$. The steady rise in contact resistance can be attributed to the accumulation of wear debris at the contact interface, caused by abrasion of the $\mathrm{Au}$ layer. A similar rise in contact resistance in soft-Au coated 


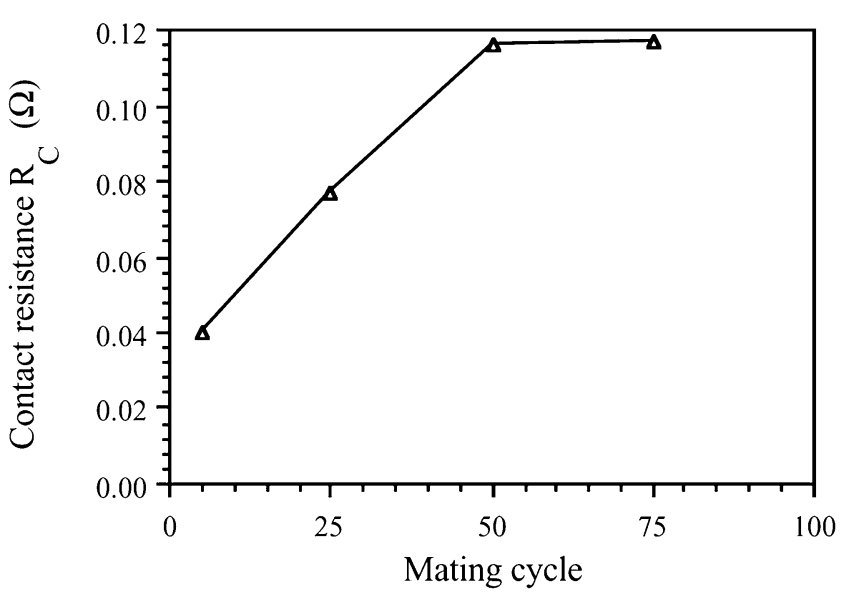

a)

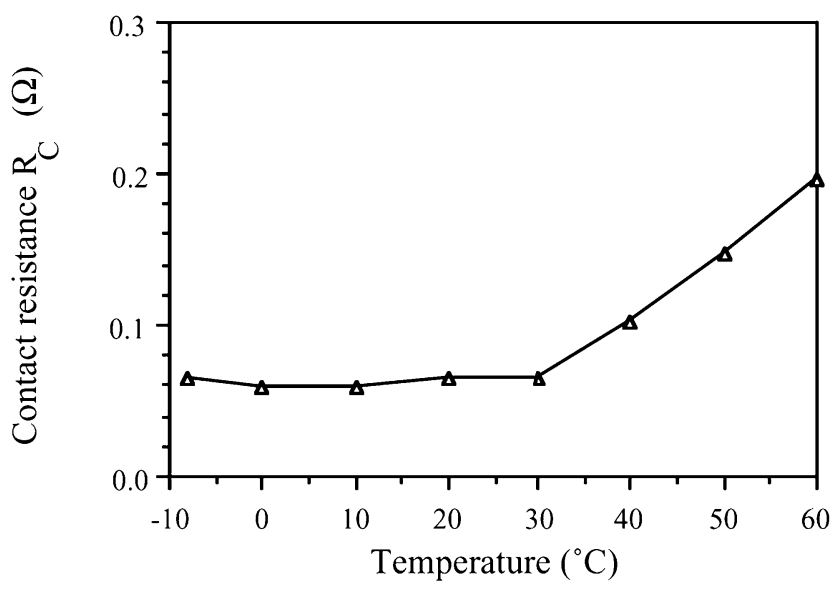

b)

Fig. 11. a) Variation of $R_{C}$ with mating cycle number. b) Variation of $R_{C}$ with temperature.

sliding contacts subjected to repeated mating cycles at $150^{\circ} \mathrm{C}$ has been reported [39]. The use of a harder Co-Au may improve resilience to sliding contact wear.

\section{Temperature Dependence of Contact Resistance}

A mated connector was heated using a Peltier element, to investigate the thermal stability of contact resistance. As previously described, a temperature rise is expected to increase the downward deflection of the conductors, reducing contact force and increasing $\mathrm{R}_{\mathrm{C}}$.

Fig. 11(b) shows the effect of temperature on contact resistance $R_{C}$ between -8 and $60^{\circ} \mathrm{C}$. Here, the data has been adjusted to account for variations in conductor resistivity caused by temperature changes. A rise with temperature may be seen, from a value of $59 \mathrm{~m} \Omega$ at $10{ }^{\circ} \mathrm{C}$. This increase is ascribed partly to bimetallic deformation of the conductors, and partly to the similar (and larger) substrate deformations previously described. The slight rise in contact resistance below $0{ }^{\circ} \mathrm{C}$ can be attributed to the reduction in contact area due to ice formation. These results suggest that further work is needed to obtain a temperature-stable device.

\section{CONCLUSION}

A novel MEMS electrical connector has been proposed, and a three-mask fabrication process devised to fabricate initial prototypes. The structure is based on a silicon substrate that has been terraced into a nonplanar profile. The result is an in-line connector with shaped elastic conductors capable of out-of-plane deflection. This configuration has advantages over the in-plane alternative, in that contact force can be maximized without affecting connector density, and multilayered conductors can be formed to optimize both mechanical strength and contact resistance. Substrate terracing is carried out using inexpensive anisotropic wet chemical etching. The process allows the formation of features to ensure precise self-alignment between conductor elements during mating, ensuring predictable contact force and eliminating short circuits. Electrophoretic photoresist is used to allow lithography on nonplanar features, and thus form an effective mould for thick spring conductors. The proposed application is for a miniature in-line connector; however, the process is compatible with Si-based microelectronics and could allow direct connection to circuitry.

The resilience of elastic conductors to sliding contact during mating and demating cycles has been demonstrated, and initial values of contact resistance are encouragingly low. Limited repeatability in the contact resistance and sensitivity to temperature suggest that further work is required to obtain a predictable and stable performance, for example by incorporating athermal elastic elements. Work is now in progress to improve these aspects.

\section{ACKNOWLEDGMENT}

The authors gratefully acknowledge a number of useful discussions with Dr D. Moore of Cambridge University, Cambridge, U.K.

\section{REFERENCES}

[1] R. S. Mroczkowski, Electrical Connector Handbook. New York: McGraw Hill, 1998.

[2] F. Michel and W. Ehrfeld, "Mechatronic microdevices," in Proc. 1999 IEEE Int. Symp. on Micromechatronics and Human Science (MHS '99), Nagoya, Japan, Nov. 23-26, 1999, pp. 27-34.

[3] W. Ehrfeld, P. Hagmann, D. Munchmeyer, and E. W. Becker, "Process for the Manufacture of Mechanically Separable Multiconnectors for the Electrical Connection of Microelectronic Components, and Multiconnectors Fabricated by This Process," European Patent EP 0184608, June $18,1986$.

[4] T. Unno, M. M. I. Bhuiyan, Y. Yokoyama, S. Sugiyama, and T. Toriyama, "Micro connector for high packaging density fabricated by using UV thick photoresist," in Proc. Tech. Dig. 18th Sensor Symposium, Kawasaki-Sangyo-Shinko-Kaikan, Japan, May 29-30, 2001, pp. 165-170.

[5] T. A. Lemke, "Micromachined Silicon Beam Interconnect," European Patent EP 1083 601, Aug. 22, 2000.

[6] H. Toshiyoshi, M. Yoshio, O. Minoru, and F. Hiroyuki, "Silicon micro motherboards for three-dimensional assembling of microsystems," Trans. JIEE, vol. 118-E, pp. 444-448, 1998.

[7] A. Tixier, Y. Mita, S. Oshima, J.-P. Gouy, and H. Fujita, "3D microsystem packaging for interconnecting electrical, optical and mechanical devices to the external world," in Proc. 13th Ann. Workshop on Micro-Electromechanical Systems (MEMS 2000), Miyazaki, Japan, Jan. 23-27, 2000, pp. 698-705.

[8] C. Strandman and Y. Bäcklund, "Passive and fixed alignment of devices using flexible silicon elements formed by selective etching," $J$. Micromech. Microeng., vol. 8, pp. 39-44, 1998. 
[9] P. Boyle, D. F. Moore, and R. R. A. Syms, "Micropackaging using thin films as mechanical components," in Proc. 52nd Electronic Component and Technology Conference (ECTC2002), San Diego, CA, May 28-31, 2002, pp. 801-807.

[10] T. Ueno and M. Saito, "Electrical Connection Structure," European Patent EP 0752 587, July 7, 1996.

[11] D. J. Bartelink, "Flexible Attachment Flip-Chip Assembly," European Patent EP 0 529 503, Aug. 19, 1992.

[12] J. Fjelstad, J. W. Smith, T. H. Di Stefano, and W. Christian, "Microelectronic Connector for Engaging Bump Leads," U.S. Patent 5812 378, Sept. 22, 1998

[13] I. Khandros, G. L. Mathieu, and G. W. Grube, "Microelectronic Contact Structure and Method of Making Same," WIPO Patent WO 97/44 767, May 15, 1997.

[14] Y. Zhang, Y. Zhang, and R. B. Marcus, "Thermally actuated microprobes for a new wafer probe card," J. Microelectromech. Syst., vol. 8, pp. 43-49, 1999.

[15] I. Takahiro, R. Sawada, and E. Higurashi, "Fabrication of micro IC probe for LSI testing," Sens. Actuators, vol. A80, pp. 126-131, 2000.

[16] W. C. Young, Roark's Formulas for Stress and Strain, 6th ed. New York: McGraw Hill, 1989.

[17] R. Holm, Electric Contacts: Theory and Application, 4th ed. Berlin, Germany: Springer Verlag, 1967.

[18] D. B. Lee, "Anisotropic etching of silicon," J. Appl. Phys., vol. 40, pp. 4569-4574, 1969 .

[19] K. E. Bean, "Anisotropic etching of silicon," IEEE Trans. Electron Devices, vol. ED-25, pp. 1185-1193, 1978

[20] A. S. Holmes and R. R. A. Syms, "Self-aligning guided wave breadboard system for delay line signal processing," in Proc. 7th Int. Conf. on Fiber Optics and Optoelectronics, London, U.K., Apr. 25-27, 1989, pp. 3.4-3.9.

[21] G. W. C. Kaye and T. H. Laby, Tables of Physical and Chemical Constants and Some Mathematical Functions, 15th ed. London, U.K.: Longman, 1986.

[22] W. N. Sharpe Jr., D. LaVan, and R. L. Edwards, "Mechanical properties of LIGA-deposited nickel for MEMS transducers," in Proc. Transducers '97 IEEE, Chicago, IL, 1997, pp. 607-610.

[23] K. J. Hemker and H. Last, "Microsample tensile testing of LIGA nickel for MEMS applications," Mater. Sci. Eng., vol. A319-321, pp. 882-886, 2001.

[24] H. S. Cho, K. J. Hemker, K. Lian, J. Goettert, and G. Dirras, "Measured mechanical properties of LIGA Ni structures," Sens Actuators, vol. A103, pp. 59-63, 2003.

[25] T. Fritz, H. S. Cho, K. J. Hemker, W. Mokwa, and U. Schnakenberg, "Characterization of electroplated nickel," Microsyst. Technol., vol. 9, pp. 87-91, 2002.

[26] E. Mazza, S. Abel, and J. Dual, "Experimental determination of mechanical properties of $\mathrm{Ni}$ and Ni-Fe microbars," Microsyst. Technol., vol. 2, pp. 197-202, 1996

[27] S. Roy, S. Furukawa, and S. Mehregany, "Determination of Young's modulus and residual stress of electroless nickel using test structures fabricated in a new surface micromachining process," Microsyst. Technol., vol. 2, pp. 92-96, 1996.

[28] D. Eammons and M. R. Winkle, "Electrophoretic Deposition Process," US Patent US 4,59,2816, June 3, 1986.

[29] P. Kersten, S. Bouwstra, and J. W. Petersen, "Photolithography on micromachined 3D surfaces using electrodeposited photoresists," Sens. Actuators, vol. A51, pp. 51-54, 1995

[30] S. Hannoe and H. Hosaka, "Electrical characteristics of micro mechanical contacts," Microsyst. Technol., vol. 3, pp. 31-35, 1996.
[31] B. L. Pruitt and T. W. Kenny, "Piezoresistive cantilevers and measurement system for characterizing low force electrical contacts," Sens. Actuators, vol. A104, pp. 68-77, 2003.

[32] J. P. B. Williamson, "The microworld of the contact spot," in Proc. 27th Ann. Holm Conf. on Electrical Contacts, Chicago, IL, 1981, pp. 1-10.

[33] J. A. Greenwood and J. B. P. Williamson, "Contact of nominally flat surfaces," Proc. Roy. Soc., vol. A295, pp. 300-319, 1966.

[34] Y. C. Tai and R. S. Muller, "Measurement of Young's modulus on microfabricated structures using a surface profiler," in Proc. IEEE Micro Electro Mechanical Systems Worskhop, Napa Valley, CA, Feb. 11-14, 1990, pp. 147-152.

[35] T. V. Duggan, Stress Analysis and Vibrations of Elastic Bodies. London: Temple Press Books Ltd., 1964.

[36] J. Schimkat, "Contact materials for microrelays," in Proc. 11th Int. Workshop on MicroElectroMechanical Systems, Heidelberg, Germany, Jan. 25-29, 1998, pp. 190-194.

[37] D. Hyman and M. Mehregany, "Contact physics of gold microcontacts for MEMS switches," IEEE Trans. Comps. Packag. Tech., vol. 22, pp. 357-364, 1999.

[38] S. Majumder, W. E. McGruer, G. G. Adams, A. Zavraky, P. M. Zavracky, R. H. Morrison, and J. Krim, "Study of contacts in an electrostatically actuated microswitch," Sens. Actuators, vol. A93, pp. 19-26, 2001.

[39] C. Leung and A. Lee, "Thermal cycling induced wiping wear of conductor contacts at $150^{\circ} \mathrm{C}$," IEEE Trans. Comps. Packag. Tech., vol. 22, pp. $72-78,1999$.

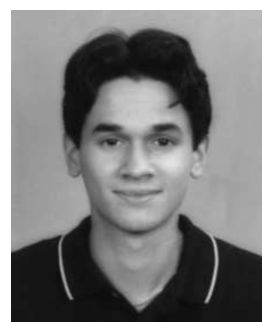

Michael P. Larsson received the M.Eng. degree in mechanical engineering from University College, London, U.K., in 2001. Presently, he is working toward the Ph.D. degree in electrical and electronic engineering at Imperial College, London, U.K.

His current interests are in the development of electrical connectors and RF MEMS devices.

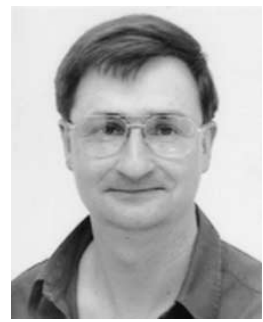

Richard R. A. Syms (M'98-SM'03) was born in Norfolk, VA, in 1958. He received the B.A. degree in engineering science and the D.Phil. degree (on volume holographic optical elements) both from Worcester College, Oxford, U.K., in 1979 and 1982, respectively.

He has been Head of the Optical and Semiconductor Devices Group in the Department of Electrical and Electronic Engineering, Imperial College London, London, U.K., since 1992 and Professor of Microsystems Technology since 1996. He has published approximately 90 papers and two books on holography, integrated optics, and microengineering. His current interests are silica-on-silicon integrated optics and silicon-based MEMS. Most recently, he has been developing microengineered mass spectrometers, optical MEMS devices, and three-dimensional self-assembling microstructures.

Dr. Syms is a Fellow of the Institution of Electrical Engineers (IEE) and a Fellow of the Institute of Physics. 